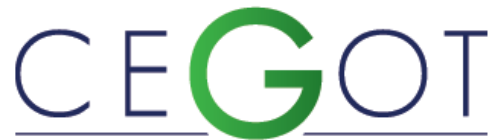

Centro de Estudos de Geografia e Ordenamento do Território
NASCIMENTO, LEANDRO

Universidade Federal de Pernambuco, Centro de Ciências Sociais Aplicadas, Programa de Pós Graduação em

Administração - PROPAD/UFPE

Av. Prof. Moraes Rego, ㄲo 1235, CCSA - Cidade Universitária, Recife - PE, CEP: 50670-901, Brasil lesnasc@gmail.com

SALAZAR, VIVIANE Universidade Federal de Pernambuco, Centro de Ciências Sociais Aplicadas, Programa de Pós Graduação em Administração - PROPAD/UFPE

Av. Prof. Moraes Rego, № 1235, CCSA - Cidade Universitária, Recife - PE, CEP: 50670-901, Brasil

viviane salazar@yahoo.com.br

\title{
Impactos do desenvolvimento imobiliário para a sustentabilidade: uma análise em Aldeia dos Camarás (Brasil)
}

Impacts of real estate development for sustainability: an analysis in Aldeia dos Camarás (Brazil)

Referência: Nascimento, Leandro; Salazar, Viviane (2018). Impactos do desenvolvimento imobiliário para a sustentabilidade: uma análise em Aldeia dos Camarás (Brasil). Revista de Geografia e Ordenamento do Território (GOT), n. ${ }^{\circ} 15$ (dezembro). Centro de Estudos de Geografia e Ordenamento do Território, p. 315-340, dx.doi.org/10.17127/got/2018.15.013

\section{RESUMO}

Com o crescimento demográfico nas principais cidades brasileiras, novas áreas estão se desenvolvendo ao redor destas cidades, a exemplo do bairro de Aldeia dos Camarás, na região metropolitana de Recife, capital do estado de Pernambuco. O presente estudo teve o objetivo de analisar o desenvolvimento imobiliário em Aldeia dos Camarás e seus impactos para a sustentabilidade nas dimensões ambiental, social e econômica. A pesquisa consiste numa análise de abordagem qualitativa, com entrevistas semiestruturadas. A análise dos relatos demonstrou a existência de impactos positivos nas dimensões social e econômica e de impactos negativos na dimensão ambiental. Além disso, identificou-se a importância do Estado no apoio das Organizações da Sociedade Civil para o fortalecimento das ações de políticas públicas em prol do bem estar social e da sustentabilidade local.

Palavras-chave: Desenvolvimento Imobiliário; Sustentabilidade; Impactos positivos e negativos; Políticas Públicas; Aldeia dos Camarás.

\section{ABSTRACT}

With demographic growth in the main Brazilian cities, new areas are developing around these cities, such as the Aldeia dos Camarás neighborhood, in the metropolitan area of Recife, capital of the state of Pernambuco. The objective of this study was to analyze the real estate development in Aldeia dos Camarás and its impacts for sustainability in the environmental, social and economic dimensions. The research consists of a qualitative approach analysis, with semi-structured interviews. The analysis of the reports showed the 
existence of positive impacts on the social and economic dimensions and negative impacts on the environmental dimension. In addition, it was identified the importance of the State in supporting Civil Society Organizations in order to strengthen public policy actions in favor of social welfare and local sustainability.

Keywords: Real estate development; Sustainability; Positive and negative impacts; Public policy; Aldeia dos Camarás.

\section{Introdução}

Nas últimas décadas, o Brasil vem sofrendo profundas transformações na organização territorial, com base em aspectos como desconcentração espacial da indústria, reestruturação produtiva e abertura econômica (Braga e Matos, 2017). Contudo, além da influência econômica, outros aspectos ainda pouco explorados como as questões socioambientais, também influenciam na reorganização territorial.

Com o crescimento demográfico nas principais cidades brasileiras, novas áreas estão se desenvolvendo ao redor destas cidades para abrigar aquelas pessoas que buscam novas formas de moradia que garantam qualidade de vida, segurança e contato com a natureza. 0 conceito de bairros projetados como a franquia Alphaville que tem se difundido no país é um exemplo disso. E esse fenômeno também está acontecendo na capital pernambucana.

Na região metropolitana do Recife (RMR), o bairro de Aldeia dos Camarás, no município de Camaragibe, possui as características ideais para satisfazer pessoas que querem morar próximo à capital pernambucana, mas também querem ter um contato mais próximo com a natureza, e por isso tornou-se uma região potencial para novos empreendimentos imobiliários que buscam explorar as áreas não utilizadas ou subutilizadas dessa região.

Com o avanço do processo de desenvolvimento imobiliário em Aldeia dos Camarás, extensas glebas de terras são utilizadas para a criação de empreendimentos imobiliários que buscam integrar qualidade de vida ao convívio com a natureza. Há de se questionar, no entanto, como o desenvolvimento imobiliário impacta no âmbito da sustentabilidade em Aldeia dos Camarás.

Ressalta-se que pesquisas prévias na região analisaram o processo de mudança do solo proveniente da intensificação da urbanização (Silva, 2015), os laços afetivos dos moradores 
pela região (Andrade, 2006), e a geração de empregos advinda do processo de periurbanização (Silva, 2012). Entretanto, não foram identificados estudos prévios que analisem o processo de urbanização e seus impactos para a sustentabilidade nesta localidade.

Diante da problemática supracitada, o presente estudo possui o objetivo de analisar o desenvolvimento imobiliário em Aldeia dos Camarás e seus impactos para a sustentabilidade nas dimensões ambiental, social e econômica. Assim, é importante caracterizar os tipos de empreendimentos imobiliários em expansão na localidade e identificar os efeitos ocasionados pelo desenvolvimento imobiliário. Importa também avaliar as ações de políticas públicas acerca dos impactos acarretados pelos empreendimentos imobiliários.

A pesquisa consiste numa análise de abordagem qualitativa, visto que pretende analisar as ações do desenvolvimento imobiliário em Aldeia dos Camarás e seus impactos no âmbito da sustentabilidade (ambiental, social e econômica). Com relação aos procedimentos, realizaram-se entrevistas semiestruturadas para analisar os aspectos subjetivos dos respondentes acerca do tema pesquisado. Além disso, foi necessário realizar levantamento bibliográfico, sendo importante a análise da legislação em vigor, mas também de artigos científicos, livros e demais fontes que caracterizem os tópicos da pesquisa, na qualidade de estudos relevantes até ao momento nessas áreas do conhecimento.

Destarte, o presente estudo possui importância para moradores e entidades, mostrando como o desenvolvimento imobiliário impacta a região e se as ações e políticas públicas são eficientes na manutenção da sustentabilidade. Será assim possível que os grupos de interesse possam rever a efetividade das ações utilizadas e/ou criar novas formas de prevenir impactos negativos para regiões no âmbito da sustentabilidade. Ressalta-se que todas as citações provenientes de língua inglesa ou espanhola incluídas neste trabalho foram livremente traduzidas para a língua portuguesa. 


\section{Revisão da literatura}

Nesta seção são abordados aspectos provenientes da literatura acerca do desenvolvimento imobiliário, da sustentabilidade e da região de Aldeia dos Camarás.

\subsection{Considerações sobre o desenvolvimento imobiliário}

Com o crescimento populacional e o anseio das famílias em adquirir o lar próprio, o desenvolvimento imobiliário ganha força em diversas áreas da RMR. Em Aldeia dos Camarás, não ocorre de forma diferente, pois a grande quantidade de glebas de terras que antes abrigavam criação de animais ou serviam para a agricultura hoje são utilizadas para a construção de novas moradias.

Contudo, as construções em Aldeia dos Camarás não contam com prédios (edifícios com vários andares plurifamiliares), mas com casas de até dois pavimentos (unifamiliares), conforme legislação em vigor que proíbe a construção de prédios na região por estar em área de preservação ambiental e de proteção de mananciais do estado e do município (Camaragibe, 1997; Pernambuco, 1986, 1987).

Avançando a discussão acerca das características territoriais, os loteamentos nada mais são do que o desmembramento de grandes parcelas de terra em lotes menores, podendo ser abertos ou fechados - funcionando como condomínios. Os condomínios horizontais são formados por lotes e geralmente possuem clubes com piscinas, parques, quadras e vários atrativos que propiciam diversão dentro do próprio condomínio. Assim, percebe-se que tanto o loteamento fechado quanto o condomínio possuem mesma forma física, diferenciando-se pela delimitação de sua constituição legal.

Em uma compreensão "quanto à origem dos condomínios/loteamentos fechados, estes se firmaram apenas com o advento da modernidade, com o avanço do capitalismo e o surgimento do fenômeno de segregação, típico da cidade moderna." (Raposo, 2008, apud Silva et al., 2012, p. 03). Ainda conforme Silva et al. (2012, p. 04) "a literatura nacional e internacional trata como condomínios fechados, os loteamentos e desmembramentos do solo urbano, com fins habitacionais, com separação física do restante da cidade." 
Dessa forma, ao longo deste trabalho adotar-se-á a denominação de condomínios também para os loteamentos fechados, já que possuem a mesma forma de funcionamento, com a característica marcante de muros, grades ou cercas que separam o complexo habitacional do restante da cidade. Adentrando o aspecto social, é possível inferir que "aqueles que escolhem habitar esses espaços valorizam viver entre pessoas seletas [...] e longe de interações indesejadas, movimento, heterogeneidade, perigo e imprevisibilidade das ruas." (Silva et al., 2012, p. 04).

Acrescenta-se a isso a qualidade de vida e o contato com a natureza que são fatores fundamentais para que haja migração das famílias da capital Recife para Aldeia dos Camarás. Como afirma Costa (2003), apud Costa e Peixoto (2007, p. 318) "os loteamentos fechados vêm se espalhando rapidamente pelo espaço urbano brasileiro, forjando novos conceitos de moradia, justificados pelo discurso da segurança e da qualidade ambiental".

Dessa forma, ter uma residência no bairro é sinônimo de status e demonstra o poder econômico que a família possui. Isso, tendo como base a presença marcante de famílias com poder aquisitivo de médio para alto na região e o padrão elevado das construções que se integram em meio às paisagens naturais formadas pela mata atlântica.

Pelo ponto de vista econômico, a presença da beleza natural fornecida pelas reservas de mata na região aumenta a valorização dos imóveis, o que impacta de forma positiva na expansão imobiliária. E segundo Costa e Peixoto (2007, p. 318) “[...] os atributos e a qualidade ambiental do espaço vêm passando a fazer parte do produto imobiliário, agregando-Ihe valor na forma de renda diferencial [...]".

Somando as paisagens naturais com a diminuição da poluição sonora, a qualidade do ar, das águas, o ambiente harmonioso e a segurança para que as crianças possam brincar livremente dentro dos condomínios formam um conjunto atrativo que compensa o valor cobrado pelas construtoras. E o sucesso de vendas aliado a crescente demanda impulsiona a criação de novos empreendimentos.

Ao abordar a migração dos empreendimentos imobiliários para as áreas mais afastadas do centro das cidades, Silva (2015, p. 14) cita alguns dos principais motivos: "a poluição visual, sonora e do ar, o excesso populacional, os congestionamentos, o lixo, os problemas estruturais, a pobreza etc. tornaram-se elementos da cidade contemporânea que 
contribuíram para seu processo de saturação". Assim, a procura por novas regiões se intensifica, gerando um processo de periurbanização, cujas características morfológicas, funcionais e socioculturais respondem mais aos modelos rurais do que urbanos (Sexto e González, 1993).

O atrativo do bairro para fortalecer a construção de loteamentos ou condomínios se dá pelas características naturais que agradam aos que buscam tranquilidade, paz e harmonia com a natureza. Para Mendéz (2002), existe uma discussão recente na literatura sobre a necessidade de se utilizar os recursos endógenos de cada região para embasar o desenvolvimento local. Dessa compreensão, os recursos ou ativos naturais são utilizados pelas organizações como meios para impulsionar o valor comercial dos empreendimentos imobiliários. Assim, esses recursos possuem um valor que não corresponde a nenhum tipo de capital real, sendo comercializadas as expectativas sobre benefícios futuros e não o valor produtivo (Vives e Rullan, 2014).

Para as empresas investidoras, esse tipo de valorização do empreendimento gera especulação imobiliária e garante bom retorno financeiro, demonstrando a compreensão de que "a especulação adquire um significado profundo na dinâmica instável do capitalismo global" (Harvey, 1982, apud Vives e Rullan, 2014, p. 401). Como investimento, "o capital intelectual vem há décadas operando em condições vantajosas [...], com ganhos decorrentes dos mecanismos formadores da renda da terra, particularmente a renda diferencial [...]" (Ball, 1977, apud Costa e Peixoto, 2007, p. 318).

Assim, as ações de empresas como incorporadoras e construtoras geram um processo de financeirização imobiliária, tendo como condição e meio o espaço tornado mercadoria e como produto as áreas urbanas (Miele, 2008). No capitalismo moderno, "na medida em que a dependência de todo o processo de financeirização progressiva da terra cresceu, o mercado imobiliário, indiretamente, foi totalmente integrado aos circuitos globais de capital em sintonia com as expansivas políticas empresariais [...]" (Vives e Rullan, 2014, p. 388). Portanto, as práticas financeirizadas possuem caráter complexo e multifacetado que abrange um aumento de transações econômicas e relações sociais no capitalismo contemporâneo, sendo esse caráter expansivo que sugere a necessidade de análise da relação entre financeirização e a produção do espaço urbano (Sanfelici, 2013). 
O aumento da comercialização no mercado imobiliário pode ser compreendido no Brasil como consequência da abertura de crédito imobiliário para segmentos de rendas que antes não possuíam acesso a estas novas formas de financiamento. Como resultado desse processo, "o volume de unidades habitacionais financiadas no Brasil saltou de uma média de 250 mil por ano, entre 2000 e 2005, para mais de 1 milhão em 2010 [...]" (Sanfelici, 2013, p. 35). Além disso, é importante ressaltar que a evolução da legislação hipotecária é compreendida como outro fator propiciador da financeirização do solo (González, Mantiñan e Miró, 2016; Vives e Rullan, 2014).

Muitos estudos vêm tentando analisar a trama de relações econômicas e sociais que permite reler a produção do espaço por meio da noção de financeirização em vários países, sendo que existe um crescimento da quantidade de pesquisas (ainda que não sejam explicitamente) sobre estas questões no Brasil (Sanfelici, 2013). Ainda segundo o autor (p. 41, aspas do autor), o fundamento do processo de financeirização do solo "repousa sobre a capacidade extraordinária - e as formas inovadoras - de incorporadoras de "escavar" rendas por todo o tecido metropolitano, modificando-o profundamente como resultado desse processo". Como consequência, a financeirização do solo pode ocasionar a existência de crises sociais, caracterizadas por lutas em torno da distribuição de riqueza (González, Mantiñan e Miró, 2016). Assim, compreende-se que:

o território brasileiro se espacializa segundo uma lógica de desigualdade, onde os processos de desenvolvimento das relações sociais são caracterizados, por um lado, pelo processo de modernização tecnológica, generalizando-se informações e mercados e, por outro, pela fragmentação - que explode territórios, onde o espaço se configura em mercadoria, com periferias que materializam mecanismos de exclusão social e segregação espacial, em sua dinâmica de urbanização (Borelli, 2007, p. 02).

Assim, os processos de transformação do capitalismo contemporâneo são responsáveis pelo crescimento desigual e têm sido fundamentais para o processo de expansão urbana e metropolitana, com caracterização de criações sociais de ordem espacial que atraem quantidades cada vez maiores de pessoas, materiais, energia, conhecimento e capital para sua existência e funcionamento, ao mesmo tempo em que geram marginalidade, resíduos e contaminantes (Artigues e Rullan, 2007). Além das questões sociais, esse processo de desenvolvimento imobiliário impacta diretamente em condições ambientais ao longo das construções (desmatamento, poluição de nascentes, etc.) e a preocupação nesse sentido impulsionou a criação de leis de proteção ambiental no Brasil. 


\subsection{Sustentabilidade e políticas públicas}

Com o avanço da globalização e o aumento do consumo generalizado ao longo dos anos, as nações começaram a questionar as consequências dessa evolução para o meio ambiente e as sociedades. Diante disso, o termo desenvolvimento sustentável surgiu como forma de garantir a continuidade dos recursos para a manutenção da vida. Assim, "o desenvolvimento sustentável é aquele que atende às necessidades do presente sem comprometer a capacidade das gerações futuras satisfazerem as suas próprias necessidades." (CMMAD Comissão Mundial para o Meio Ambiente e o Desenvolvimento, 1991, p. 46). E como afirmam Savitz e Weber (2007, p. 02):

o termo se originou da conscientização crescente, durante a década de 1980, de que os países precisavam descobrir maneiras de promover o crescimento de suas economias sem destruir o meio ambiente ou sacrificar o bem estar das futuras gerações.

Aprimorando esse conceito, chega-se ao termo 'sustentabilidade' que possui três dimensões, a saber - social, ambiental e econômica que juntas podem garantir a efetividade do desenvolvimento sustentável. Dessa forma,

[...] a sustentabilidade, como o desempenho dos negócios, é vista através da integração de responsabilidade financeira, social e ambiental, que é através do uso racional dos recursos naturais e financeiros, bem como o respeito pelas pessoas e todas as criaturas vivas (Ahmić, Šunje e Kurtić, 2016, p. 881).

Para Barbieri e Silva (2011) o termo desenvolvimento sustentável vem sendo substituído pela palavra sustentabilidade. Essa transformação se dá principalmente pelos conceitos adotados no campo de estudos organizacionais, onde as ações devem focar não apenas o retorno financeiro, mas garantir a manutenção da vida nas comunidades e a preservação dos recursos ambientais. Entende-se que a sustentabilidade passa a integrar a ação de organizações e não apenas o papel do poder público como ocorre na expressão desenvolvimento sustentável. Assim, "sustentabilidade, um substantivo abstrato, já não carrega mais as questões relativas ao desenvolvimento e, entre elas, as ideias de projetos políticos conduzidos pelo interesse público" (Barbieri e Silva, 2011, p. 70).

Analisando a sustentabilidade pelo desenvolvimento imobiliário, percebe-se que organizações como as construtoras devem pugnar pelo fornecimento de um produto que garanta a necessidade das famílias, contribuindo com a preservação ambiental e cumprindo a função de geração de lucros para os acionistas, de forma a induzir o desenvolvimento econômico da região, a exemplo da criação de empregos. Porém, é preciso analisar a área 
do empreendimento, entender os impactos das obras e traçar um plano de ação para evitar danos no âmbito da sustentabilidade. E segundo Almeida (2002), a sustentabilidade exige uma postura preventiva, que identifique tudo que um empreendimento pode fazer de positivo para ser maximizado, e de negativo, para ser minimizado. Assim, entende-se que

cada vez mais, as empresas terão que incluir em seus processos de desenvolvimento a avaliação dos impactos sociais, ambientais e econômicos, para atender às expectativas da opinião pública e, assim, preservar sua imagem e presença no mercado. (Almeida, 2002, p. 82).

Entretanto, muitas organizações não atentam para a importância da sustentabilidade e preocupam-se apenas com a geração de lucros e dividendos. Deste entendimento, compreende-se que a gestão pública precisa intervir por meio de regulação e medidas fiscais para que o crescimento não ocorra de forma desordenada (Artigues e Rullan, 2007). Assim, o crescimento dos empreendimentos imobiliários em longa escala levaram as entidades públicas a regulamentar as construções, principalmente por meio de legislação para fiscalização e regularização das obras.

Segundo Costa (2006), apud Costa e Peixoto (2007), o Estado incorporou princípios da modernização ecológica, como a tendência crescente de utilização de procedimentos e instrumentos da legislação ambiental nos processos de regulação das atividades urbanas. Seja por meio de Leis Federais, Estaduais ou Municipais, as empresas estão enfrentando constantes fiscalizações que visam evitar ou mitigar os impactos não desejáveis no tripé da sustentabilidade.

Contudo, não apenas o Estado, mas diversas entidades de cunho público ou privado estão focadas em ações para fiscalizar as atitudes que possam impactar de forma negativa o funcionamento das sociedades ou o meio ambiente. No nível federal (Brasil) existe o Instituto Brasileiro do Meio Ambiente e dos Recursos Naturais Renováveis - IBAMA, responsável pela fiscalização do uso dos recursos naturais; no nível estadual (Pernambuco) existe a Agência Estadual de Meio Ambiente - $\mathrm{CPRH}$, responsável pela execução da política estadual de recursos ambientais e hídricos.

Na região de Aldeia dos Camarás, existe o Fórum Socioambiental de Aldeia, que é:

[...] uma Sociedade Civil de direito privado, sem fins lucrativos, de duração indeterminada, com atuação na Região de Aldeia/PE, [...] que visa promover, acompanhar e avaliar ações para a melhoria da qualidade de vida, o fortalecimento da cidadania, o desenvolvimento socio-ambiental, estimulando o comprometimento da comunidade com a segurança e preservação do meio- 
ambiente, tendo como base precípua o desenvolvimento sustentável e a inclusão social (Forum Socioambiental de Aldeia, 2005).

O Fórum é composto por moradores da região e semanalmente é feita uma reunião para discutir os problemas da área, propor melhorias e planos de ação conjunta entre órgãos públicos e privados para garantir a preservação do meio ambiente e a manutenção da qualidade de vida na localidade.

Muitas ações em prol da sustentabilidade fazem parte das políticas públicas instauradas pelo Estado. Conforme Appio (2005), a Constituição Federal do Brasil de 1988 assegura a proteção ambiental e a qualidade de vida por meio da implantação de políticas públicas. Segundo Salheb et al. (2009) as políticas públicas se constituem em intervenções do Estado, em conjunto ou não com a sociedade civil (ONGs, grupos empresariais, comunidades, entidades internacionais, etc.).

Dessa forma, "as políticas públicas ambientais assumiram papel primordial de proteger o meio ambiente, integrando sua proteção aos demais objetivos da vida em sociedade, como forma, inclusive, de proporcionar qualidade de vida" (Salheb et al., 2009, p. 12). E as entidades estatais aliadas às entidades privadas como o Fórum Socioambiental de Aldeia mostram como as ações conjuntas (público-privado) podem fortalecer as causas comuns em prol da sustentabilidade para a região de Aldeia dos Camarás.

\subsection{Conhecendo a região - Aldeia dos Camarás}

Situado no município de Camaragibe/PE, na RMR, o bairro Aldeia dos Camarás possui esse nome por conta das tribos indígenas que habitavam a região. A principal via de acesso para o bairro é a rodovia PE-027, conhecida popularmente como Estrada de Aldeia, com extensão de 13 quilômetros $(\mathrm{km})$ até o limite do município. A Figura 01 mostra o mapa de Aldeia dos Camarás, destacando a Estrada de Aldeia (rodovia PE-027) que atravessa todo o bairro.

Porém, segundo o Departamento de Estradas de Rodagem de Pernambuco (2011) a rodovia PE-027 possui um total de $38,60 \mathrm{~km}$, sendo que se inicia em Camaragibe e termina na cidade de Araçoiaba, perpassando vários municípios ao longo de sua extensão.

A extensão atual de Aldeia é de $31.9 \mathrm{~km}^{2}$, representando $59.17 \%$ do município do qual se integra [...]. Sua porção norte se limita com os municípios de Abreu e Lima 
e Paudalho; a leste com a cidade do Recife; São Lourenço da Mata faz limite na porção oeste, e ao sul está o município de Camaragibe (Andrade, 2006, p. 138).

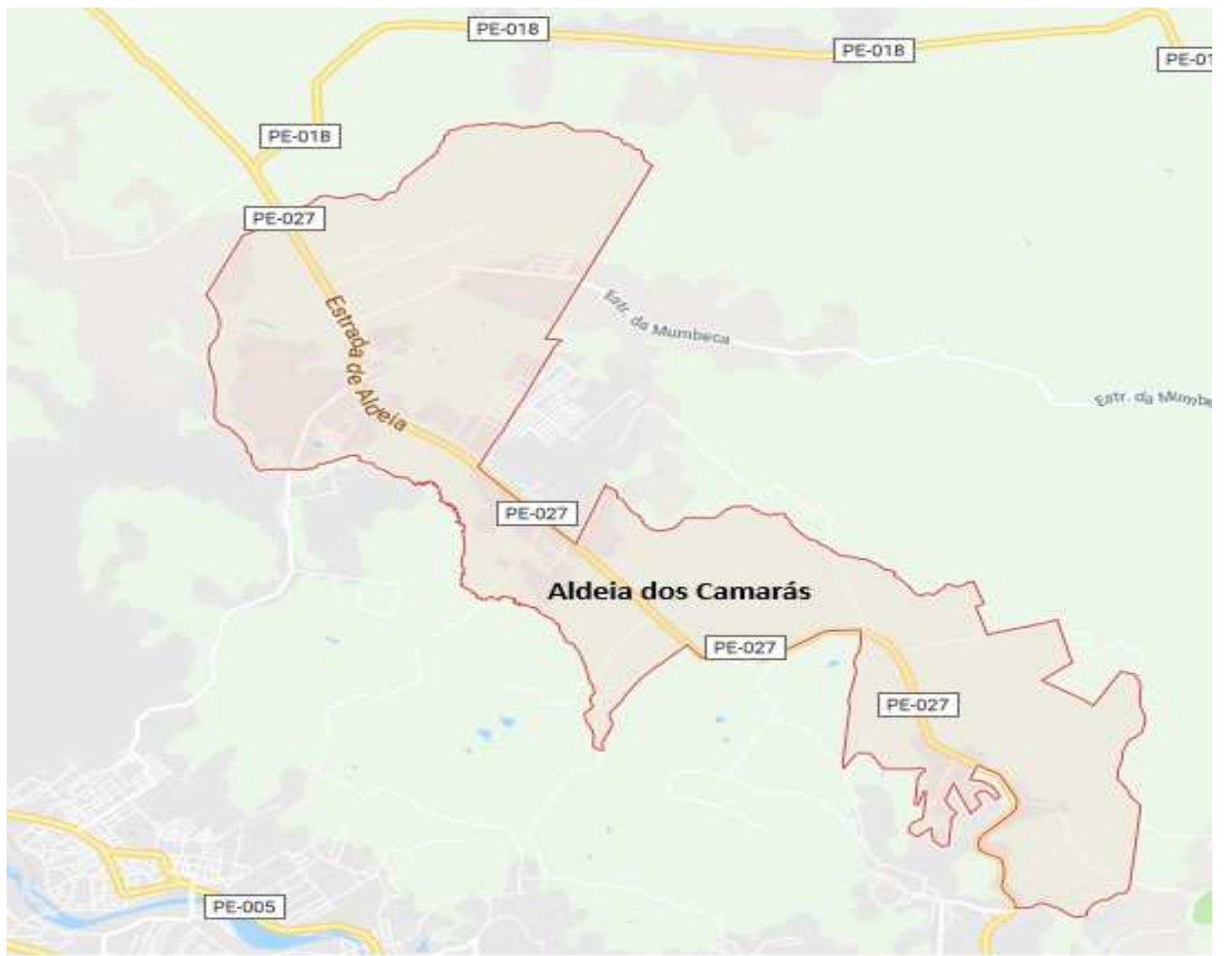

Figura 01 - Demarcação da Estrada de Aldeia (PE-027) que perpassa todo o bairro. Fonte: Adaptado do Google Maps - online.

Coforme o Censo Demográfico realizado em 2010 (IBGE - Fundação Instituto Brasileiro de Geografia e Estatística, 2010), Aldeia dos Camarás possui 6.460 habitantes, correspondente a $4.50 \%$ do total de habitantes do município de Camaragibe. Dessa forma, a existência de menos de $5 \%$ da população municipal inserida em um bairro cuja extensão territorial corresponde a mais de $50 \%$ do solo da cidade, gera indícios de que o bairro de Aldeia dos Camarás ainda não atingiu seu potencial máximo de ocupação do solo, constituindo um atrativo para o investimento imobiliário na região. Do total de habitantes do bairro, $49.33 \%$ são mulheres e $50.67 \%$ são homens, havendo uma média de 3.3 moradores por domicílio. Acerca da faixa etária, os habitantes com idade entre 15 a 64 anos correspondem a $67.7 \%$ do total populacional (IBGE - Fundação Instituto Brasileiro de Geografia e Estatística, 2010).

Estando a uma altitude de 55 metros do nível do mar (SECID - Secretaria das Cidades, 2010) e com a presença de grandes reservas de mata atlântica e nascentes de rios, a região de Aldeia dos Camarás se beneficia de um clima ameno que agrada os habitantes. Mesmo sendo definida como área urbana pelo Plano Diretor do Município de Camaragibe 
(Camaragibe, 2007), o bairro possui características de área rural e perpassa a sensação de tranquilidade (Andrade, 2006).

A Figura 02 mostra por imagem de satélite o bairro de Aldeia dos Camarás e sua grande extensão de mata atlântica - região verde, comparando esta região com a capital Recife onde é possível identificar um alto índice de construções e de ocupação do solo.

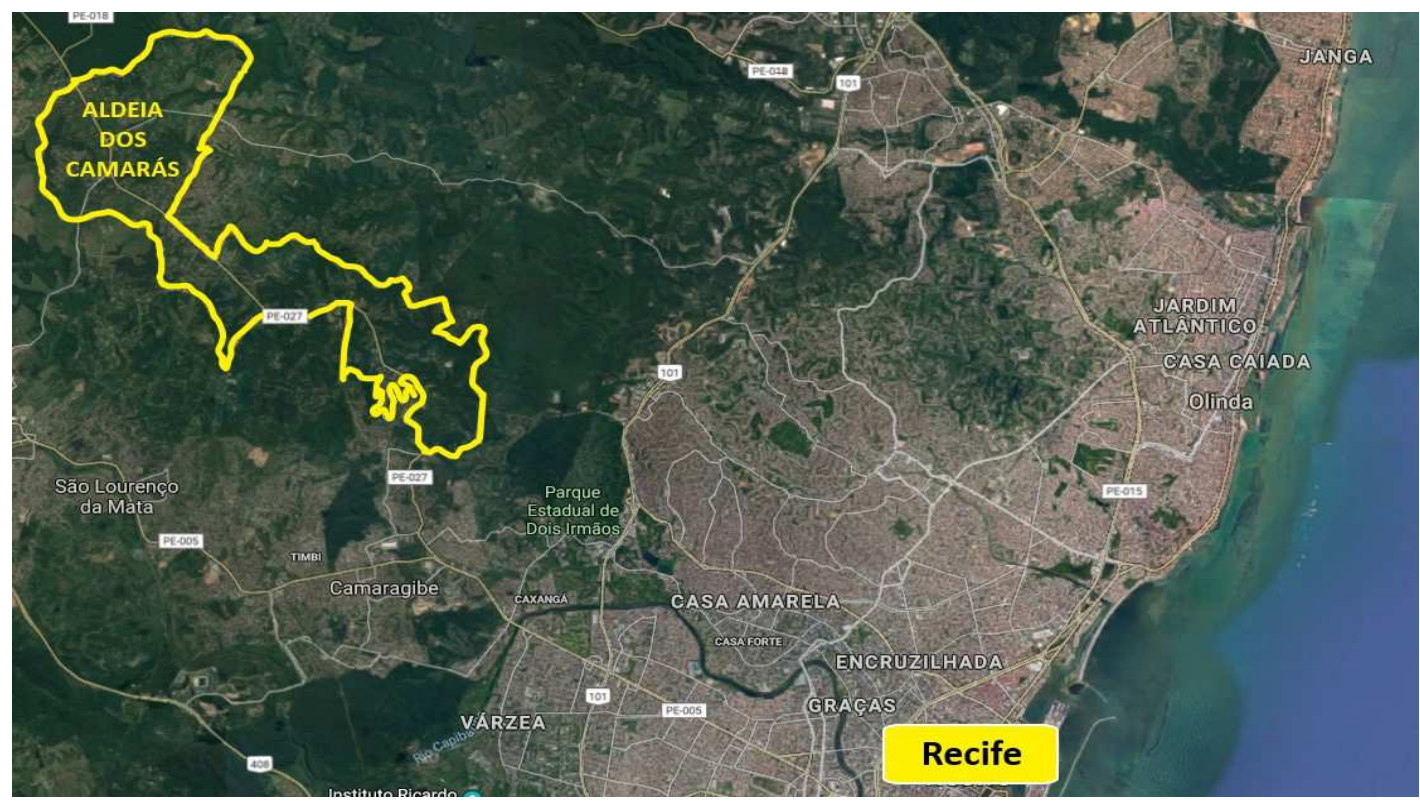

Figura 02 - Comparação da área verde entre o bairro de Aldeia dos Camarás e a capital Recife. Fonte: Adaptado do Google Maps - online.

A sensação de tranquilidade (Andrade, 2006), aliada à proximidade com a capital Recife atrai um público que cada vez mais deseja morar no bairro. Seja para moradia ou para desfrutar de momentos agradáveis aos finais de semana, as chácaras, sítios, granjas e condomínios horizontais residenciais têm atraído as famílias que buscam criar os filhos ou mesmo viver de forma pacata; com segurança, qualidade de vida e contato com a natureza.

A busca crescente pela moradia no bairro causa mudanças na forma de urbanização da região, como afirma Andrade (2006, p. 141) "Com o fim das atividades do Engenho Camaragibe, no início do século XX, a área em estudo passou por mudanças de uso e ocupação do solo, sendo repartida em glebas, e posteriormente, granjas e loteamentos".

Assim, a região passou a ser fracionada, onde as chácaras, granjas e até fazendas foram e continuam sendo divididas em loteamentos ou condomínios de lotes de terras. Estas ações impulsionam a oferta de terras na região e aquecem o mercado imobiliário, com o lançamento de diversos empreendimentos habitacionais. 


\section{Metodologia}

A pesquisa consiste numa análise exploratória e de abordagem qualitativa, visto que pretende analisar as ações do desenvolvimento imobiliário em Aldeia dos Camarás e seus impactos para a sustentabilidade. Para Silveira e Córdova (2009) a pesquisa qualitativa preocupa-se com aspectos da realidade que não podem ser quantificados, centrando-se na compreensão e explicação da dinâmica das relações sociais.

Com relação aos procedimentos, é importante a análise da legislação em vigor, como também, de artigos científicos e demais fontes que caracterizem os tópicos da pesquisa, a exemplo da sustentabilidade, do mercado imobiliário e da região de Aldeia dos Camarás. Esse levantamento bibliográfico auxilia na compreensão dos temas abordados e no desenvolvimento da revisão narrativa da literatura - utilizada neste estudo.

A revisão narrativa da literatura "[...] é utilizada para descrever o estado da arte de um assunto específico, sob o ponto de vista teórico ou contextual" (Botelho, Cunha e Macedo, 2011, p. 125). Além disso, baseia-se na percepção e interpretação pessoal do pesquisador (Bernardo, Nobre e Janete, 2004).

A fim de analisar a relação entre o desenvolvimento imobiliário e as questões socioambientais, foram realizadas entrevistas semiestruturadas com três respondentes, para entender qual a percepção destes acerca do processo de desenvolvimento imobiliário e dos impactos (positivos e/ou negativos) para a região.

A escolha dos respondentes ocorreu pela necessidade de entender a percepção de três atores importantes no processo de desenvolvimento do bairro: 1) a visão do presidente do Fórum Socioambiental de Aldeia; 2) a visão do diretor de meio ambiente da prefeitura municipal; e 3) a visão do diretor de uma imobiliária que atua na região.

A seleção desses três atores sociais se deu por conta da sua importância no âmbito da diversidade de comportamentos e das posições que cada ator possui dentro do mesmo campo social, contribuindo com visões que podem ser distintas e ao mesmo tempo complementares para a análise aqui proposta. 
A ordem de realização das entrevistas se deu conforme a disponibilidade dos entrevistados, ocorrendo entre maio e junho de 2017, sendo que o presidente do Fórum Socioambiental de Aldeia foi entrevistado via Skype. As entrevistas tiveram uma média de duração entre $36 \mathrm{~min}$ e $01 \mathrm{~h} 35 \mathrm{~min}$ e foram gravadas e posteriormente transcritas. Utilizou-se como base para essas transcrições algumas normas descritas por Marcuschi (2007), que facilitaram a compreensão e a análise das entrevistas.

Os dados empíricos coletados nas entrevistas foram submetidos à análise de conteúdo, conforme recomendações propostas por Bardin (2009). Segundo esta autora (p. 40), "a análise de conteúdo aparece como um conjunto de técnicas de análise das comunicações que utiliza procedimentos sistemáticos e objectivos de descrição do conteúdo das mensagens (itálico da autora)". Especificamente, dentro da análise de conteúdo proposta por Bardin (2009), utiliza-se como forma de classificação das entrevistas a análise temática permitindo uma divisão do texto em alguns temas principais, que se pode aperfeiçoar, eventualmente, em subtemas.

Assim, as entrevistas tiveram a importância de gerar uma base para analisar a visão de três atores acerca do desenvolvimento imobiliário e as consequências deste no tripé da sustentabilidade para o bairro. Os três respondentes são moradores do bairro e contribuem com uma visão holística acerca das questões da região, fortalecendo a importância dos relatos. Além disso, as entrevistas buscam identificar se as políticas públicas utilizadas são eficientes no controle dos impactos indesejados.

A utilização do recurso online Skype como meio para entrevistar o presidente do Fórum gerou uma limitação na compreensão do discurso por falhas de conexão na internet, onde muitos trechos e palavras da entrevista ficaram incompreensíveis. Ademais, outra limitação identificada nesta pesquisa é a quantidade reduzida de entrevistados, sendo compreensível que a inclusão de mais respondentes poderia melhorar o entendimento dos fenômenos analisados, principalmente porque os entrevistados neste trabalho além de moradores são representantes de organizações e, assim, podem apresentar certo viés nas respostas - como se identificará nos relatos do diretor empresarial. 


\section{Apresentação e análise dos resultados}

Os respondentes foram identificados pelas abreviações dos cargos que ocupavam: O Diretor da Imobiliária é identificado pela abreviatura DIR-EMP (Diretor Empresarial); para o Diretor de Meio Ambiente da Prefeitura, foi usada DIR-MA (Diretor de Meio Ambiente); e, para o Presidente do Fórum Socioambiental de Aldeia, a sigla PRE-FOR (Presidente do Fórum).

Analisa-se a temática desse estudo em três categorias constantes na Tabela 01. As categorias temáticas emergiram da análise dos dados, mediante a recorrência nas entrevistas e a importância desses temas nos relatos. Como as discussões acerca dessas temáticas são interdisciplinares, a análise é feita de forma a salientar os pontos abordados pelos respondentes numa ordem cronológica, conforme foram expostas nas entrevistas.

\begin{tabular}{ll}
\hline Categorias & Subtemas \\
\hline $\begin{array}{l}\text { Desenvolvimento } \\
\text { Imobiliário }\end{array}$ & $\begin{array}{l}\text { Tipos de empreendimentos imobiliários; } \\
\text { Relevância e impactos para o bairro. } \\
\text { Sustentabilidade }\end{array}$ \\
$\begin{array}{l}\text { Dimensão econômica; Dimensão social; } \\
\text { Dimensão ambiental. }\end{array}$ \\
\hline Políticas Públicas & $\begin{array}{l}\text { Legislação municipal, estadual e federal; } \\
\text { Organizações da sociedade civil. }\end{array}$ \\
\hline Tabela 01- Categorias de análise temática do conteúdo \\
Fonte: Elaborado pelos autores
\end{tabular}

\subsection{Desenvolvimento imobiliário - relevância e impactos socioambientais}

Acerca dos empreendimentos imobiliários, verifica-se um consenso pelos entrevistados do tipo que se intensifica na região de Aldeia dos Camarás, sendo os condomínios horizontais. Esses emprendimentos possuem as mesmas características dos condomínios fechados descritos por Silva et al. (2012) e atendem a legislação que proíbe a construção de condomínios verticais para preservar os ativos ambientais da região de Aldeia dos Camarás (Camaragibe, 1997).

Para os entrevistados, a questão da segurança é vista como um fator relevante para a intensificação e o surgimento dos condomínios horizontais que baseiam o desenvolvimento imobiliário no bairro e percebe-se a questão da segregação e homogeneização entre classes sociais descritas por Silva et al. (2012) como um dos motivos que leva esse público a optar por esses seletos empreendimentos:

DIR-MA: Então, esse tipo de condomínio tem atraído muito a atenção das pessoas porque entra a questão segurança [...]. 
Para os entrevistados, esse tipo de empreendimento oferece maior segurança para os moradores, o que demonstra a preocupação dos brasileiros com os altos índices de violência e insegurança vivenciados em várias regiões do país.

É perceptível também a preocupação com o aumento populacional, quando o relato abaixo transcrito demonstra a satisfação do respondente por não se ter condomínios verticais no bairro, indicando o cumprimento da LEl 032/97 em vigor (Camaragibe, 1997) pelos empreendedores:

PRE-FOR: Por enquanto, a gente pode até comemorar... Por enquanto ainda são horizontais.

Além disso, os entrevistados abordam visões distintas sobre a importância do desenvolvimento imobiliário, como: a transferência legal de manutenção da localidade (recolhimento de lixo, limpeza e preservação de ruas, etc.) do município para os moradores dos condomínios, que traz uma perspectiva econômica; e verifica-se a questão da ordem e do disciplinamento no crescimento imobiliário na região, realçando o papel das entidades públicas como controladoras desse desenvolvimento, mostrando a importância da legislação e do papel do Estado no cumprimento de suas leis, que constitui uma premissa básica no campo das políticas públicas segundo Salheb et al. (2009).

Essas visões distintas demonstram a importância que cada ator releva acerca do desenvolvimento imobiliário, estando o DIR-EMP preocupado com uma abordagem econômica, comum no ambiente dos negócios e nos contextos organizacionais para geração de lucros. Já o DIR-MA baseia sua visão na preocupação do Estado com a organização do crescimento imobiliário e nas condições de vida para o bem estar da sociedade, dando ênfase ao cumprimento dos parâmetros legais, conforme relatos:

\footnotetext{
DIR-EMP: Em minha opinião tem toda relevância. Primeiro, que para o município é muito bom. $O$ custo de implantação é todo do empresário, do incorporador. 0 município tem uma arrecadação de IPTU. Tem arrecadação de ISS na construção. E tem toda uma comodidade de não ter a responsabilidade de fazer a manutenção. DIR-MA: Eu identifico o seguinte: tudo aquilo que é passível de ser disciplinado, que você consegue mensurar, que você consegue organizar, que você consegue planejar, ele é melhor do que aquele crescimento desordenado. Então esse tipo de empreendimento, imobiliário, condomínio, ele tem que cumprir regras no FIDEM que é um dos órgãos que autoriza, depois ele tem que cumprir regras no CPRH e depois ele tem que cumprir regras no município.
}

Com relação aos efeitos ocasionados pelo desenvolvimento imobiliário, alguns aspectos foram expostos, como a visão de que os novos moradores do bairro querem melhor qualidade de vida, principalmente o contato com a natureza, mas não abrem mão dos 
avanços existentes na capital, exercendo um papel de mudança e transformação nas características do bairro, principalmente por querer integrar características da capital a uma região conhecida como 'semirural'. Essa busca pelos atributos e a qualidade ambiental no bairro é condizente com o que Costa e Peixoto (2007) definem como agregação de valor diferencial ao empreendimento, mas também contribui com o surgimento de impactos negativos no âmbito da sustentabilidade, conforme visão crítica de um dos entrevistados:

PRE-FOR: E hoje a gente vê uma coisa diferente, as pessoas que sobem, sobem querendo levar... o que elas tinham na cidade. Elas querem associar o benefício de viver mais próximo da natureza, mas trazendo toda uma carga de problema para uma região que ainda conserva aspectos... de preservação da natureza e... cria uma dicotomia difícil de existir essas coisas.

Foi possível identificar, por meio dos relatos, características inerentes ao processo de financeirização do solo (González, Mantiñan e Miró, 2016; Sanfelici, 2013) condizentes com a utilização dos recursos naturais endógenos da região (Mendéz, 2002) como atributos que impulsionam a apropriação do solo local como uma forma de capitalização para as empresas (Vives e Rullan, 2014) envolvidas e beneficiadas com o processo de desenvolvimento imobiliário no bairro.

\subsection{Sustentabilidade - dimensões econômica, social e ambiental}

Há uma consciência de que o crescimento imobiliário traz benefícios positivos, a exemplo da geração de empregos (na dimensão social) e do crescimento do comércio local (na dimensão econômica), que são compreendidos como consequências do aumento populacional acarretado pelo surgimento dos condomínios horizontais no bairro.

Além disso, é perceptível que os empregos que surgem em grande maioria não requerem elevado grau de instrução e escolaridade, sendo específicos para pessoas de classes sociais mais baixas e com baixo nível de escolaridade que moram em comunidades próximas, sendo até uma crítica feita pelo entrevistado PRE-FOR em seu relato, onde afirma que o surgimento de empregos em grande maioria é para "servidores dos condomínios". Isso parece traduzir uma relação de hierarquia social, condizente com a asserção exposta por Silva $(2012$, p. 85$)$ de que "a valorização do rural tem levado parte da classe média recifense a deslocar-se para localidades do entorno da RMR, dentre elas Aldeia, e este movimento gera oportunidades de trabalho". Seguem relatos: 
DIR-EMP: Existem no meu ver três impactos importantes. Primeiro, a geração de emprego. Certo? Que... emprega desde o pedreiro da construção até o jardineiro quando a casa esta pronta. A empregada doméstica e outros... porteiros, zeladores, certo!? O segundo impacto que eu vejo: o comércio regional. Aumenta muito o comércio, é bom para o comércio. Por quê? O aldeense tem, por exemplo, um condomínio tipo, de duzentos lotes, duzentas unidades. Na construção, tem duzentas famílias que vão consumir... produtos de Aldeia. Por exemplo, padaria, açougue, supermercado, petshop... Entre outros.

PRE-FOR: Claro! Claro... (incompreensível) mas o custo disso, o que você perde que são os ativos ambientais, que nas gerações futuras não terão, se você botar no balanço você questiona isso, né? O aumento da população criou, cria empregos num bairro [...], por exemplo, que emprego vai criar ali? Vão criar os porteiros, os servidores dos condomínios...

No relato supracitado (PRE-FOR) o entrevistado aponta os problemas que, a seu ver, são mais importantes que avaliar o crescimento do comércio e a geração de empregos, demonstrando que o crucial não é o aumento do trabalho ou da economia locais, mas os aspectos de preservação do ecossistema que constituem a dimensão ambiental da sustentabilidade. E de forma histórica, todo o processo de desenvolvimento do Brasil se deu através da exploração agressiva e predatória dos recursos naturais como madeira e metais preciosos (Salheb et al., 2009), algo que nos dias atuais infelizmente ainda ocorre.

Outro ponto relatado pelos entrevistados é o aumento no fluxo do trânsito na Estrada de Aldeia, que traz consequências não só sociais, mas também ambientais, como o atropelamento de animais que cruzam a PE-027. Isso mostra que não só a ocupação do solo com as construções afeta a fauna ao alterar seu habitat natural, mas também o aumento no fluxo de veículos e a falta de preocupação e de consciência dos motoristas em dirigir com cuidado e dentro dos limites de velocidade levam à morte de animais silvestres nas estradas:

DIR-MA: Olha, outro impacto que a gente não citou, é trânsito! Então, quando eu aumento a densidade populacional de uma área, automaticamente eu vou ter um fluxo de veículos muito maior se dirigindo para aquele local. Então, numa área de preservação ambiental, o que é que a gente tem visto? Muitos animais atropelados na estrada por conta desse fluxo de trânsito.

Em relação à captação de água para atender a demanda de novas moradias, os respondentes afirmam que por não haver abastecimento de água na região, a alternativa é a perfuração de poços. Logo, existe a preocupação de que os lençóis freáticos venham a diminuir o volume de água na região por conta do aumento da captação da água no subsolo para atender às novas moradias em suas necessidades básicas e não básicas, como as piscinas, conforme relatos que seguem abaixo. E como Castro (2007) afirma, o 
desenvolvimento urbano contribui significativamente para alteração de questões hidrológicas, como a quantidade e a qualidade da água.

DIR-EMP: Hoje temos água em Aldeia... proveniente de perfuração de poços.

PRE-FOR: Por exemplo, eu vivi num sítio onde eu observava isso. Eu tinha uma cacimba, e quem tem cacimba, quem não tem poço, a abundância de água em Aldeia é tão grande que praticamente eu captava água com treze, quatorze metros. Mas ao longo de quinze anos que eu vivi, praticamente eu tive que cavar quinze metros. Os poços são mais profundos, vai demorar mais a sentir esse impacto.

O bairro não conta com rede de saneamento básico, sendo necessária a construção de fossas sépticas com valas e sumidouros que retêm os dejetos sólidos. Mas assim deposita-se no solo o líquido proveniente desses dejetos, traduzindo outra preocupação na dimensão ambiental - contaminação de águas subterrâneas usadas para consumo da população. Essas fossas são aprovadas pelo órgão competente $(\mathrm{CPRH})$ e um dos entrevistados acredita que dentro dos condomínios essas normas são mais eficientes, principalmente pela facilidade de controle e fiscalização que se possui por se tratar de um empreendimento planejado e pela concentração de várias residências em uma única localidade. Conforme relatado:

DIR-EMP: O sistema de... saneamento básico no bairro, em quase todo bairro de Aldeia... ele se dá através de fossa séptica. Que também é regulamentado pelo CPRH. Então você tem um sistema de fossa que você tem... a questão dos sumidouros, certo? E das valas infiltradoras.

PRE-FOR: Eu acho que... fazer um controle num condomínio é mais fácil... porque o condomínio é uma entidade que por si só tem uma organização... e até pro CPRH ele esta concentrado. Fazer isso num território mais (incompreensível) como o território das granjas é mais difícil.

Existem impactos negativos ocasionados pelas construções imobiliárias, mas também se percebe a importância da consciência da população para realizar denúncias aos órgãos competentes, como também a importância da fiscalização e a necessidade de se usar a legislação para impedir os avanços dessas ações negativas para o meio ambiente:

DIR-MA: JÁ! Nesses casos a gente faz a fiscalização, as vistorias... recentemente a gente teve um caso desses. Então, o empreendedor quando a gente foi... avisado, houve a denúncia porque nisso entra aí a consciência de quem é morador de uma área como essa, ele tem essa consciência de dizer: opa, alguém fez um desmatamento ali, será que a prefeitura está informada? Aí vem a denúncia. Foi uma subtração de uma área de vegetação às margens de um córrego.

Entretanto, reforçando a questão acerca do conhecimento sobre alguma ação de desmatamento ou poluição de nascentes de rios, um dos entrevistados (DIR-EMP) relatou um caso de desmatamento ocorrido antes da construção de um parque no km 10 da Estrada de Aldeia, não se referindo aos empreendimentos imobiliários como ocasionadores desse desastre ambiental. 
Diante desse relato, percebeu-se que o respondente não entrou em detalhes e ausentou qualquer responsabilidade do desmatamento como consequência de uma ação ocasionada pelo crescimento imobiliário e pela ação de empresas do ramo. Então, perguntou-se aos outros dois respondentes nas entrevistas subsequentes qual o conhecimento deles acerca desse fato e os mesmos relataram que esse desmatamento ocorreu para construção de um empreendimento imobiliário e que a população se manifestou contra esse crime ecológico, de modo que a prefeitura desapropriou a área em questão para transformá-la em um parque, como citado:

DIR-MA: Esse parque surgiu exatamente porque essas pessoas que optaram em morar mais distante como eu ia dizendo, elas optaram por um motivo: a consciência ambiental delas. Então, o que é que o pessoal percebeu? Que uma área grande com muitas jaqueiras que de repente, da noite pro dia foi colocada... a eixo do chão como a gente diz, cortada ali próximo da raiz. E foi uma quantidade tão grande que chocou os moradores, se mobilizaram, fizeram... uma interdição na PE-027 com faixas, cartazes... Um protesto grande que naquele momento sensibilizou a gestão municipal pra desapropriar e tornar uma área pública. A prefeitura quando adquiriu já foi porque houve uma comoção da sociedade pelo desmatamento, então um desmatamento foi provocado pelo proprietário da área pra fazer o que? Um loteamento!

Dessa forma, compreende-se que a visão empresarial busca se ausentar dos problemas socioambientais causados pelos empreendimentos imobiliários, o que pode ser compreendido como uma forma de evitar um julgamento social e consequentemente, a diminuição de vendas de imóveis, visto que os consumidores possuem consciência dos impactos ambientais e evitam comprar de empresas que não atuam de forma ambientalmente correta.

Essa consciência ambiental mostra quão importante é a participação dos moradores para a manutenção dos recursos ambientais e o bom funcionamento das políticas públicas, conforme Salheb et al. (2009, p. 06) “a crise ambiental fez com que a sociedade se mobilizasse, exigindo - dos poderes constituídos - respostas mitigadoras e propulsoras de um novo modelo societário".

\subsection{Políticas públicas - legislação e organizações da sociedade civil}

Um dos entrevistados, ao expor sua visão, argumentou que o crescimento imobiliário não gera problemas ambientais, pois as empresas obedecem à legislação e a fiscalização impede que esses problemas existam. Percebe-se que o cumprimento de ações em prol da 
sustentabilidade na construção dos empreendimentos imobiliários da região se dá como uma conformidade às legislações e não como ação consciente das empresas. Dessa forma, ressalta-se a importância da legislação (políticas públicas) e da intervenção dos moradores como ações em prol da sustentabilidade, auxiliando no controle da atuação indevida das organizações:

DIR-EMP: Veja só... o que... falava-se muito antigamente era que impactava na região em questão ambiental. Que eu não vejo esse problema em Aldeia, por quê? Temos um Plano Diretor no município onde temos as diretrizes municipais, depois é passado para as diretrizes estaduais e regido por uma Lei federal.

DIR-EMP: Se não houvesse, sim! Por que iria ser desordenado. Mas como há ordem, ordenação das construções, o empreendedor primeiro passa por uma consulta prévia...

Buscando compreender ações além da função do Estado, perguntou-se se outras entidades exerciam um papel importante de fiscalização e regulação do desenvolvimento imobiliário no bairro, sendo citado o Fórum Socioambiental de Aldeia pelos três respondentes, como destacado em um dos relatos:

DIR-MA: Uma das mais respeitadas organizações não governamentais do estado na área ambiental é o Fórum socioambiental de Aldeia. Porque é um grupo da sociedade que se organizou e disse: olha, não adianta eu estar reclamando do meio ambiente sentado à borda da minha piscina rodando o meu copo de uísque... eu tenho que dar a minha contribuição.

Assim, "as reivindicações de direitos na seara ambiental estão marcadas por uma nova sensibilidade de atores sociais que começam a abrir os olhos para a relação diretamente estabelecida entre a questão ambiental e a sadia qualidade de vida das gerações atuais e futuras" (Salheb et al., 2009, p. 18).

Entretanto, o entrevistado PRE-FOR informa no próximo relato que o papel do Fórum não é de fiscalização, mas de apoiar a comunidade a resolver problemas, por meio da intermediação com as entidades públicas competentes, que converge com o entendimento de Salheb et al. (2009, p. 06) de que "qualquer que seja o ponto de partida de análise de políticas públicas, ele pressupõe o olhar sobre pressões sociais, interesses conflitantes, interesses comuns, jogos de poder, instituições, intervenções, dentre outros".

PRE-FOR: Um dos objetivos do Fórum é fazer a intermediação dos problemas da comunidade com as instituições públicas... E então o que a gente faz é isso. Nós não somos um órgão de fiscalização, não temos nem como objetivo ser, mas a gente tem como objetivo levar aos órgãos públicos de uma forma minimamente estruturada as denúncias e os problemas de Aldeia.

O Fórum possui espaço para discutir as ações em prol da comunidade com o poder público municipal, estadual e federal, conforme o entrevistado PRE-FOR citou em seu relato. Isso se 
dá pelo tempo de existência da organização e o reconhecimento pelas lutas em prol do bairro, o que gerou um reconhecimento para a mesma. Dessa forma, é reconhecível que:

Em inúmeros países está se vivenciando uma abertura do poder Executivo à participação de atores societários - organizações civis - investidos juridicamente como representantes de determinados segmentos e interesses da população no desenho, na implementação e na supervisão de políticas públicas (Lavalle, Houtzager e Castello, 2006, p. 43).

Ao longo dos relatos, os entrevistados frisaram a criação de um projeto para o bairro chamado 'De Olho em Aldeia'. O projeto foi criado pelo Fórum e mostra como a comunidade pode contribuir com a melhoria do bem estar social por meio de políticas públicas, não necessariamente idealizadas pelo Estado:

DIR-MA: O Socioambiental propôs o De Olho em Aldeia, que são as câmeras pra monitoramento. Esse projeto ele foi encampado... foi idealizado pelo Fórum Socioambiental de Aldeia.

DIR-EMP: Tem hoje uma segurança em Aldeia chamada De Olho em Aldeia. [...] você vê tudo, tem tempo se acontecer alguma coisa. Até acidente o pessoal vê e chama, chega SAMU, chama a Polícia.

Percebe-se que essa ação busca melhorar a questão da segurança para o bairro, contribuindo para a qualidade de vida da população. A ideia partiu de uma organização da sociedade civil, não pelo poder público. Mesmo assim, o próprio governo estadual se recusou a ajudar na construção do projeto, alegando falta de recursos e sugerindo que uma função do Estado (segurança pública) fosse desempenhada pelos próprios moradores do bairro. Isso expõe as limitações de um país com altos índices de arrecadação tributária, mas que não consegue cumprir com uma necessidade básica para o bem estar social - a segurança dos cidadãos:

PRE-FOR: É muito complicado porque o (Ciods) SDS ele nem contribui com a câmera nem com a estrutura e quando a gente disse tudo bem, a gente vai botar tudo isso e vai mandar as imagens pra vocês, eles disseram... não pode, porque nós não temos como (monitorar) essas imagens, vocês teriam que custear os agentes aqui pra... e aí ficou inviável.

Contudo, a nova gestão municipal recebeu o projeto e se comprometeu com a criação de uma central de monitoramento, permitindo assim a viabilidade do projeto concebido pelo Fórum. Como o Diretor de Meio Ambiente do município de Camaragibe é um ex-integrante do Fórum, acredita-se que sua participação como integrante da gestão municipal foi crucial para estimular a atual gestão a viabilizar a implantação do projeto De Olho em Aldeia:

PRE-FOR: Um fato muito recente que aconteceu há dois meses... três meses atrás é que a nova gestão da prefeitura se ofereceu pra receber as imagens e fazer a monitoração dessas imagens. 
Contudo, compreende-se que a representatividade e o reconhecimento do Fórum como uma organização comprometida com os moradores do bairro foi essencial para que a prefeitura decidisse apoiar o projeto elencado. Acerca desse papel de intermediação das organizações civis, Lavalle, Houtzager e Castello (2006, p. 52) confirmam que "[...] as funções de intermediação levadas a cabo pela entidade conseguem abrir portas e franquear o acesso a instâncias de tomadas de decisão no poder público; instâncias que, de outra forma, permaneceriam inalcançáveis para os beneficiários".

Visto o papel do Fórum para o bairro, questionou-se se havia uma divulgação das ações do Fórum para a população e os respondentes DIR-MA e PRE-FOR afirmaram que há uma precariedade nessa comunicação.

Mas se essa comunicação não ocorre, como os moradores poderão saber o que o Fórum está fazendo e como participarão das ações para contribuir na execução dos projetos idealizados pelos integrantes do Fórum? Assim, é preciso que os integrantes se esforcem no sentido de tornar públicas as ações do Fórum, atraindo a atenção dos moradores para que mais pessoas apoiem as iniciativas e participem ativamente nos projetos e nas ações em prol de Aldeia dos Camarás e de sua sustentabilidade.

\section{Conclusão}

A análise dos relatos dos entrevistados demonstrou a existência de impactos positivos (geração de empregos e melhoria da rede de comércio local) nas dimensões social e econômica e também de impactos negativos (desmatamento, diminuição do volume de água no subsolo e atropelamento de animais silvestres) na dimensão ambiental, dentro de uma abordagem para a sustentabilidade. Essas consequências são decorrentes do desenvolvimento imobiliário que se intensifica no bairro de Aldeia dos Camarás, principalmente pela modalidade conhecida como condomínios horizontais, que é um tipo de empreendimento imobiliário crescente no bairro.

Entretanto, percebe-se que as ações de políticas públicas, principalmente a ação do Estado pela legislação e da mobilização dos moradores por meio do Fórum Socioambiental de 
Aldeia, constituem um papel crucial para a manutenção dos ecossistemas, para a regulação dos empreendimentos imobiliários e para a fiscalização e controle de ações prejudiciais no âmbito da sustentabilidade.

Ressalta-se a importância do Estado no apoio das organizações da sociedade civil, a exemplo da prefeitura de Camaragibe/PE que apoiou o projeto De Olho em Aldeia, idealizado pelo Fórum Socioambiental de Aldeia para monitorar as ocorrências no local, por meio da implantação de câmeras de monitoramento ao longo da Estrada de Aldeia (PE-027).

Assim, o Fórum Socioambiental de Aldeia demonstra quão importante é a ação conjunta dos moradores por meio de organizações da sociedade civil para melhorar a região onde vivem, pois a população unida possui maior força e visibilidade perante os órgãos públicos para propor melhorias, cobrar ações e impulsionar o desenvolvimento social, econômico e ambiental das localidades, contribuindo para o bem estar social.

Mediante os resultados apresentados, pesquisas futuras podem analisar o processo histórico de mudanças no bairro relacionado com a ocupação do solo e as percepções de antigos e novos moradores acerca desse processo transformativo, como também, realizar uma análise aprofundada acerca da consciência socioambiental destes moradores e em como essas atitudes conscientes propiciam comportamentos proativos para a manutenção da sustentabilidade na região.

Como aprofundamento da análise exploratória desenvolvida e, tendo em vista a potencialidade de generalização dos resultados aqui elencados, pesquisas comparativas entre a RMR e demais regiões metropolitanas no Brasil podem ainda ser aplicadas para compreender se os impactos socioambientais ocorrem com mesma intensidade nas demais regiões brasileiras, permitindo uma visão abrangente e detalhada do desenvolvimento imobiliário e seus impactos para a sustentabilidade no Brasil.

\section{Referências bibliográficas}

AHMIĆ, A.; ŠUNJE, A.; KURTIĆ, E. The Influence of Top Managers' Personal Values on Sustainability of SMEs in Developing Countries. In Proceedings of International OFEL Conference on Governance, Management and Entrepreneurship. no 4, Dubrovnik - Croatia, 2016, p. 880-902. 
ALMEIDA, F. O bom negócio da sustentabilidade. Rio de Janeiro: Nova Fronteira, 2002.

ANDRADE, A. K. N. O lugar em Aldeia: significados, valores, percepções e atitudes dos moradores dos condomínios residenciais de Aldeia, Camaragibe - PE. 299 f. Dissertação (Mestrado em Geografia) Universidade Federal de Pernambuco, CFCH, Recife, 2006.

ÁPPIO, E. Controle Judicial das Políticas Públicas no Brasil. Curitiba: Juruá, 2005.

ARTIGUES, A.-A.; RULLAN, O. Nuevo modelo de producción residencial y territorio urbano disperso (Mallorca, 1998-2006). Revista Electrónica de Geografía y Ciencias Sociales, 2007, vol. 11, no 245, p. 1-17. ISSN 11389788.

BARBIERI, J. C.; SILVA, D. Desenvolvimento sustentável e educação ambiental: uma trajetória comum com muitos desafios. Rev. Adm. Mackenzie, maio/junho 2011, vol. 12, no 3, p. 51-82. ISSN 1678-6971. http://dx.doi.org/10.1590/S1678-69712011000300004

BARDIN, L. Análise de Conteúdo. 4a ed.. revista e atualizada. Trad. Luís Antero Reto e Augusto Pinheiro. Lisboa, Portugal: Edições 70, LDA, 2009.

BERNARDO, W. M.; NOBRE, M. R. C.; JANETE, F. B. A prática clínica baseada em evidências. Parte II: buscando buscando as evidências em fontes de informação. Revista da Associação Médica Brasileira, 2004, vol. 50, n 1, p. 104-108. ISSN 1806-9282. http://dx.doi.org/10.1590/S0104-42302004000100045

BORELLI, E. Urbanização e qualidade ambiental: o processo de produção do espaço da costa brasileira. Revista Internacional Interdisciplinar INTERthesis, 2007, vol. 4, no 1, ISSN 1807-1384. https://doi.org/10.5007/\%25x

BOTELHO, L. L. R.; CUNHA, C. C. A.; MACEDO, M. O método da revisão integrativa nos estudos organizacionais. Gestão e Sociedade, maio/agosto 2011, vol. 5, no 11, p. 121-136. ISSN 1980-5756. http://dx.doi.org/10.21171/ges.v5i11.1220

BRAGA, F.; MATOS, R. Quem são os migrantes das metrópoles? Uma análise comparativa das pessoas que entraram e saíram das regiões metropolitanas brasileiras. Revista de Geografia e Ordenamento do Território (GOT), junho 2017, no 11. Centro de Estudos de Geografia e Ordenamento do Território, p. 59-81, dx.doi.org/10.17127/got/2017.11.003

CAMARAGIBE. LEI 032/97, de 31 de dezembro de 1997. Disponível em:< http://www.camaragibe.pe.gov.br/2012/index.php?option=com docman\&task=doc details\&gid=1\&/temid=8 9>. Acesso em: 18 out. 2016.

CAMARAGIBE. Plano Diretor do Município de Camaragibe - Lei Complementar no 341 de 13 de julho de 2007. Disponível

em:< http://www.camaragibe.pe.gov.br/2012/index.php?option=com docman\&task=doc details\&gid=746\&ltemid =89>. Acesso em: 17 out. 2016.

CASTRO, L. M. E. Proposição de metodologia para a avaliação dos efeitos da urbanização nos corpos de água. 2007. 297 f. Tese (Doutorado em Saneamento, Meio ambiente e Recursos Hídricos) - Escola de Engenharia, Universidade Federal de Minas Gerais, Belo Horizonte, 2007.

COSTA, H. S. M.; PEIXOTO, M. C.D. Dinâmica imobiliária e regulação ambiental: uma discussão a partir do eixosul da Região Metropolitana de Belo Horizonte. Rebep, 2007, vol. 24, no 2, p. 317-336. ISSN 0102-3098. http://dx.doi.org/10.1590/S0102-30982007000200009.

CMMAD - Comissão Mundial para o Meio Ambiente e o Desenvolvimento. Our common future. Fundação Getúlio Vargas: Rio de Janeiro, 1991.

DEPARTAMENTO DE ESTRADAS DE RODAGEM DE PERNAMBUCO. Sistema Rodoviário Estadual - Rodovias Estaduais. Abr. 2011. Disponível em:< http://www.der.pe.gov.br/web/der/rodovias-do-estado>. Acesso em: 16 out. 2016.

FORUM SOCIOAMBIENTAL DE ALDEIA. Estatuto Social. Camaragibe, 13 de setembro de 2005. Disponível em:< http://forum-de-aldeia.blogspot.com.br/p/estatuto-social.html>. Acesso em: 22 out. 2016.

GONZÁLEZ, R. C. L.; MANTIÑAN, M. J. P.; MIRÓ, S. V. El proceso urbanizador en España (1990-2014): una interpretación desde la geografía y la teoría de los circuitos de capital. Revista Electrónica de Geografía y Ciencias Sociales, 2016, vol. 20, no 539, ISSN 1138-9788. 
IBGE - Fundação Instituto Brasileiro de Geografia e Estatística. Censo Demográfico 2010. Sinopse do Censo 2010. Rio de Janeiro: $2010 . \quad$ Disponível em: <https://censo2010.ibge.gov.br/sinopseporsetores/?nivel=st>. Acesso em: 19 abril 2018.

LAVALLE, A. G.; HOUTZAGER, P. P.; CASTELLO, G. Representação política e organizações civis: Novas instâncias de mediação e os desafios da legitimidade. Revista Brasileira de Ciências Sociais, fev. 2008, vol. 21, no 60, p. 43-66. ISSN 1806-9053. http://dx.doi.org/10.1590/S0102-69092006000100003

MARCUSCHI, L. A. Análise da conversação. 6. ed., São Paulo: Ática, 2007.

MENDÉZ, R. Innovación y desarrollo territorial: algunos debates teóricos recientes. EURE (Santiago), 2002, vol. 28, no 84, ISSN 0250-7161. http://dx.doi.org/10.4067/S0250-71612002008400004

MIELE, S. A. F. A cidade como negócio: o investimento no solo urbano no contexto de financeirização do setor imobiliário. In: Anais do II CINCCI, São Paulo - USP, 2008. ISBN 978-85-88126-63-3.

PERNAMBUCO. LEI No 9.860, de 12 de agosto de 1986. Disponível em:< http://legis.alepe.pe.gov.br/arquivoTexto.aspx?tiponorma=1\&numero=9860\&complemento=0\&ano=1986\&tip o=TEXTOORIGINAL>. Acesso em: 18 out. 2016.

PERNAMBUCO. LEI No 9.989, de 13 de janeiro de 1987. Disponível em:< http://legis.alepe.pe.gov.br/arquivoTexto.aspx?tiponorma=1\&numero=9989\&complemento=0\&ano=1987\&tip o=\&url=>. Acesso em: 18 out. 2016.

SALHEB, G. S. M. et al. Políticas públicas e meio ambiente: reflexões preliminares. Planeta Amazônia: Revista Internacional de Direito Ambiental e Políticas Públicas, 2009, vol. 1, no 1, p. 05-27. ISSN 2177-1642.

SANFELICI, D. Financeirização e a produção do espaço urbano no Brasil: uma contribuição ao debate. EURE (Santiago), 2013, vol. 39, no 118, p. 27-46. http://dx.doi.org/10.4067/S0250-71612013000300002

SAVITZ, A. W.; WEBER, K. A empresa sustentável: o verdadeiro sucesso é o lucro com responsabilidade social e ambiental. Tradução de Afonso Celso da Cunha Serra. Rio de Janeiro: Elsevier, 2007.

SECID - Secretaria das Cidades. Plano Metropolitano de Resíduos Sólidos - PMRS. Secretaria da Cidades -

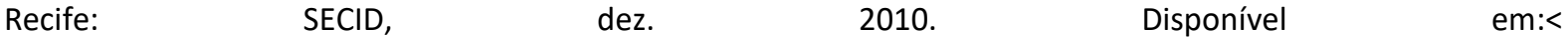
http://www.academia.edu/24308959/PLANO METROPOLITANO DE RES\%C3\%8DDUOS S\%C3\%93LIDOS PMRS Regi\%C3\%A3o Metropolitana do Recife -RMR>. Acesso em: 17 out. 2016.

SEXTO, C. F.; GONZÁLEZ, R. C. L. Estructura urbana de las áreas metropolitanas gallegas. La estructura urbana de santiago. ¿Un área metropolitana en proceso de formación? Papeles de Geografía, 1993, no 19, p. 115-124. ISSN 1989-4627.

SILVA, M. R. A. et al. Impactos sociais e urbanísticos dos loteamentos fechados no setor sul de Uberlândia - um estudo de caso. Revista Caminhos de Geografia, Uberlândia, out. 2012, vol. 13, no 43, p. 01-17. ISSN 16786343.

SILVA, A. B. As velhas e novas periferias: o caso de Aldeia (Camaragibe-PE). Revista Eletrônica da Associação dos Geógrafos Brasileiros - Seção Três Lagoas/MS, Três Lagoas, Nov. 2015, vol. 1, no 22, p. 09-26. ISSN 18082653.

SILVA, A. B. A questão periurbana e o novo espaço de oportunidades da região metropolitana do recife: o caso de aldeia (Camaragibe/PE). Revista Percurso, 2012, vol. 4, no 1, p. 85-98. ISSN 2177-3300. http://dx.doi.org/10.4025/revpercurso.v4i1.15542

SILVEIRA, D. T.; CÓRDOVA, F. P. A pesquisa científica. In: GERHARDT, T. E.; SILVEIRA, D. T. (Orgs). Métodos de Pesquisa. Coordenado pela Universidade Aberta do Brasil - UAB/UFRGS e pelo Curso de Graduação Tecnológica - Planejamento e Gestão para o Desenvolvimento Rural da SEAD/UFRGS. - Porto Alegre: UFRGS, 2009. ISBN: 978-85-386-0071-8.

VIVES, S.; RULLAN, O. La apropiación de las rentas del suelo en la ciudad neoliberal española. Boletín de la Asociación de Geógrafos Españoles, 2014, no 65, p. 387-408, ISSN 0212-9426. 